\title{
Chemical and mineralogical composition of Icelandic dust
}

\author{
CLARISSA BALDO $^{1}$, PAOLA FORMENTI ${ }^{2}$, SOPHIE \\ NOWAK $^{3}$, SERVANNE CHEVAILLIER ${ }^{2}$, MATHIEU \\ CAZAUNAU $^{2}$, EDOUARD PANGUI $^{2}$, CLAUDIA DI \\ BIAGIO $^{2}$, JEAN-FRANCOIS DOUSSIN ${ }^{2}$, KONSTANTIN \\ IGNATYEV ${ }^{4}$, PAVLA DAGSSON-WALDHAUSEROVA ${ }^{5,6}$, \\ OLAFUR ARNALDS ${ }^{5}$, A. ROBERT MACKENZIE ${ }^{1}$ AND \\ ZONGBO SHI ${ }^{1}$ \\ ${ }^{1}$ University of Birmingham \\ ${ }^{2}$ LISA, UMR CNRS 7583, Université Paris-Est-Créteil, \\ Université de Paris, Institut Pierre Simon Laplace (IPSL) \\ ${ }^{3}$ Université de Paris \\ ${ }^{4}$ Diamond Light Source \\ ${ }^{5}$ Agricultural University of Iceland \\ ${ }^{6}$ Czech University of Life Sciences Prague \\ Presenting Author: cxb637@student.bham.ac.uk
}

Iceland is a very active source of dust at high latitude. Here, chemical and mineralogical composition of dust particles from five major dust hotspots in Iceland were analysed. The aerosol samples showed a basaltic composition with relatively high total iron $(\mathrm{Fe})$ content $(10-13 \%)$. We found that Icelandic dust mineralogy is very different from Saharan dust. Amorphous basaltic material (glass) is a primary component of Icelandic dust, ranging from $8 \%$ (Hagavatn hotspot) to $60-90 \%$ (other hotspots). About $80-90 \%$ of total $\mathrm{Fe}$ is contained in aluminosilicate minerals, mainly pyroxene, and in the amorphous glass. Sequential extraction of Fe to determine its chemical form indicates that magnetite is the main $\mathrm{Fe}$ oxyhydroxide, contributing to $7-15 \%$ of the total Fe. Dithionite Fe (Fe oxides such as hematite and goethite) and ascorbate $\mathrm{Fe}$ (amorphous $\mathrm{Fe}$ oxyhydroxide) are $1-6 \%$ and $0.3-1.4 \%$ of the total Fe. In addition, we observed in Icelandic dust an initial Fe solubility of $0.08-0.6 \%$ (ammonium acetate extraction, $\mathrm{pH}$ 4.7), which is comparable to Saharan dust. The Fe solubility at $\mathrm{pH} 2$ was significantly higher than typical low latitude dust (up to 30\%). Our results confirmed the fundamental differences in composition and mineralogy between Icelandic dust and low latitude dust. We attribute these differences to the low degree of chemical weathering, basaltic composition of the parent sediments, and glacial processes. Icelandic dust contributes to the atmospheric deposition of soluble $\mathrm{Fe}$ and may impact primary productivity in the North Atlantic Ocean, which is seasonally Felimited. The distinct mineralogy and Fe speciation also suggest that the optical properties of Icelandic dust may be different from low-latitude dust. In particular, our analysis indicates that the shortwave absorption properties of Icelandic dust are determined by the high magnetite content. This suggests a potentially significant impact of Icelandic dust on the radiation balance in the sub-polar and polar regions. Our new dataset on chemical composition, mineralogy, and optical parameters of Icelandic dust can be used to estimate the radiative impact of Icelandic dust and its role on Arctic climate. 